\section{LA CONFEDERACIÓN ESPAÑOLA DE CENTROS DE ESTUDIOS LOCALES (CECEL) Y LA FEDERACIÓN ESPAÑOLA DE MUNICIPIOS Y PROVINCIAS (FEMP)}

\author{
Ernesto Fernández-Xesta y Vázquez \\ Tesorero de la CECEL
}

\begin{abstract}
The relationships and the mutual collaboration between the CECEL and the FEMP are described and specially the organization of Lessons for the continuous training in the FEMP given by members of the CECEL.
\end{abstract}

KEY WORDS: Collaboration, agreement CECEL/FEMP. Historical and Artistic Heritage. Heraldry. Studies on banners and coats of arms.

Si partimos del hecho de que la Confederación Española de Centros de Estudios Locales (CECEL), vinculada al Consejo Superior de Investigaciones Científicas (CSIC), impulsa, agrupa y coordina la actividad científica y cultural de los cincuenta y ocho centros $u$ organismos dedicados a la investigación local en ella confederados y que, bajo diferentes denominaciones, han sido creados o asumidos por Diputaciones, Comunidades Autónomas o Ayuntamientos ${ }^{1}$, no debe extrañarnos demasiado que, entre sus diferentes fines, se encuentren los de impulsar los estudios de investigación local, promoviendo actividades diversas, tales como proyectos de investigación, congresos, seminarios, cursos, encuentros, etcétera, o promover las relaciones entre sus Centros y las de éstos con los del CSIC, Universidades y otras instituciones españolas y extranjeras de análoga finalidad².

Ello ha llevado a su Junta de Gobierno a plantearse, en su momento, la colaboración directa con la Federación Española de Municipios y Provincias (FEMP), como asociación de Entidades Locales que agrupa Ayuntamientos, Diputaciones, Consejos y Cabildos Insulares, en un total más de 6.900 municipios españoles y que, dentro de los servicios que presta a los mismos, se encuentra el de la Formación Continua integral al servicio de los procesos de moder-
THE SPANISH CONFEDERATION OF CENTRES OF LOCAL STUDIES (CECEL) AND THE SPANISH FEDERATION OF PROVINCES AND MUNICIPALITIES (FEMP)

RESUMEN: Se describen las relaciones y mutua colaboración entre la CECEL y la FEMP y, entre ellas, la organización de Cursos de Formación Continua de la FEMP impartidos por miembros de la CECEL.

PALABRAS CLAVE: Convenio de colaboración CECEL/FEMP. Patrimonio Histórico Artístico. Heráldica. Vexilología.

nización de la Administración Local, con una importante singularidad: estar dirigido al personal del conjunto de los Entes Locales del Estado.

Para ello, el entonces presidente de la CECEL, don José Carlos Valle Pérez, director del Museo de Pontevedra, firmó con la entonces presidenta de la FEMP, doña Rita Barberá Nolla, alcaldesa de Valencia, en Madrid, en el mes de mayo del año 1998, un Convenio de colaboración, en el que, entre otros objetivos se encuentra el de la organización conjunta de actividades culturales, tales como congresos, mesas redondas, seminarios, etc. ${ }^{3}$, con el fin de un permanente asesoramiento y una formación continua en las diferentes materias que se considerasen necesarias.

A finales del año 2005, y en reunión de la actual presidenta de la CECEL, la doctora doña Ángela Madrid y Medina, presidenta del Instituto de Estudios Manchegos, a quien acompañaban el representante del CSIC en la CECEL, doctor don Wifredo Rincón García y el tesorero de la misma, don Ernesto Fernández-Xesta y Vázquez, con don Alberto Torres Pérez, entonces secretario general de la FEMP, por ausencia del anterior presidente, el excelentísimo señor don Francisco Vázquez Vázquez, alcalde de La Coruña, 
acompañado por el director de coordinación Técnico-Jurídica de la propia Federación, don Gonzalo Brun Brun, se acordó que, como inicio de esta colaboración acordada con anterioridad, la CECEL propondría, como iniciativa inicial, dos cursos a incluir en los planes de Formación Continua de la FEMP; uno de ellos sería sobre Patrimonio Histórico Artístico; el otro, sobre Heráldica y Vexilología de las Entidades Locales; la idea tuvo una gran acogida en la FEMP, y se acordó que la CECEL encargaría a personas o instituciones propias la preparación de ambos proyectos, que se presentarian a la FEMP para su estudio $y_{\text {, en }}$ su caso, posterior inclusión dentro de los planes anuales de Formación Continua de dicha asociación.

El curso relativo al Patrimonio Histórico Artístico fue encargado al prestigioso doctor don Wifredo Rincón García, investigador científico del CSIC, conocido experto en Historia del Arte y representante del CSIC en la Junta de Gobierno de la CECEL, el cual, por imponderables profesionales, no ha podido centrar totalmente el curso.

El otro curso, el relativo a la Heráldica y Vexilología de las Entidades Locales, fue encargado a la Real Academia Matritense de Heráldica y Genealogía, para que fuese preparado a través de quien escribe esta breve reseña. Si bien por causas de programación este curso no ha podido ser incluido entre los que se impartieron dentro del programa de Formación Continua de la FEMP, ya ha sido entregado su borrador a dicha Federación para estudiar la posibilidad de introducirlo entre los que se impartan a partir de ahora.

Este curso de Heráldica y Vexilología de las Entidades Locales españolas ha sido concebido con un doble objetivo; de un lado, el práctico, comentando diversas normas y formas de aprobación, modificación o rehabilitación de los diferentes símbolos emblemáticos de las Entidades Locales, existentes en diferentes Comunidades Autónomas -hasta seis: Andalucía, Aragón, Cataluña, Galicia, Madrid y País Vasco-, como muestreo de todas las demás, y el proceso normal de presentación de propuestas; y el teórico general, acerca de la Heráldica y la Vexilología, la Heráldica Municipal y otra simbología; se incluyen, además, como se verá en el programa propuesto, amplias e importantes referencias a las Jornadas de Heráldica Municipal de Játiva y de Zaragoza, como referente obligado a la idea de una posible unificación de normativa y procedimiento de aprobación, modificación o rehabilitación de estos símbolos emblemáticos de las En- tidades Locales, culminando en la propuesta de estudio de la cuestión de la necesidad de creación de un único Corpus Emblemático de las Entidades Locales españolas.

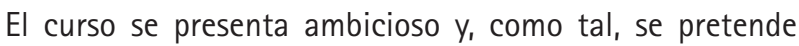
que los diferentes ponentes sean los mejores especialistas o profesionales en sus distintos campos; bien es verdad que, en conjunto, se han buscado miembros de la Real Academia Matritense de Heráldica y Genealogía, numerarios o correspondientes, pero tratando de que procedan de diversas Comunidades Autónomas, para lograr, así, una visión de conjunto de la situación actual en estas materias; aparecen, asimismo, dentro del cuadro de posibles ponentes, otras personas destacadas por su propia andadura profesional. De este modo, se intenta dar una imagen plural, propia de lo que es la CECEL, en cuanto que la engloban centros de todo el Estado, incluidos, o no, en organismos oficiales, pero siempre independientes y con personalidad propia. Y estos centros, además, no se debe olvidar que están integrados por personas, expertas en diversas materias, independientes, libres y autónomos.

La actividad formativa se ha propuesto con la finalidad de la impartición de un total de 24 horas, entre un lunes y un jueves; seis horas diarias, cuatro matutinas y dos por la tarde, con los descansos necesarios para café y comida; estaría dirigido a alcaldes, concejales, secretarios de Ayuntamientos y sus homónimos en Diputaciones y Cabildos Insulares, en un número máximo, por curso, de 30 a 40, y, al finalizar, los alumnos recibirían un diploma, propio de la Formación Continua, con la emblemática propia de la FEMP, la CECEL y la Real Academia Matritense de Heráldica y Genealogía, certificando que han asistido con aprovechamiento al curso.

Así, el programa propuesto por la CECEL para este curso básico de Heráldica y Vexilología Municipales, incluiría las siguientes materias:

- La Emblemática.

- Teoría general de la Heráldica (I y II).

- Principios fundamentales de la Vexilología.

- La Heráldica municipal (I y II).

- Ejemplos de la situación de las normas actuales de Heráldica y Vexilología de las Entidades Locales en Galicia, el País Vasco, Aragón, Cataluña, Andalucía y Madrid.

- Los "imagotipos" en la simbología local actual. 
- El "diseño heráldico" y el blasonamiento.

- El "diseño vexilológico" y la descripción de las banderas.

- El Patrimonio Histórico Artístico español.

- La Heráldica y la Vexilología como Patrimonio Histórico Artístico.

- Los intentos de unificación de los principios de Heráldica y Vexilología en España: Las Jornadas de Heráldica Municipal de Játiva y de Zaragoza.

- Las conclusiones de las Jornadas de Heráldica Municipal de Zaragoza. Futuro de las Jornadas de Heráldica Municipal.

- Las conclusiones de las Jornadas de Heráldica Municipal de Zaragoza y las actuales normas de "diseño" de la Heráldica y la Vexilología de las Entidades Locales (I y II).

- El proceso de la presentación de los escudos y banderas para su aprobación; los "expertos heráldicos" o empresas de estudios heráldicos y la propuesta de escudo y de bandera municipales.

- La figura del "Cronista" en el estudio previo del proceso de propuesta de escudo y bandera municipales.

- Propuestas generales para la unificación de las normas del "diseño" y del blasonamiento o descripción de escudos, banderas e imagotipos.

- La divulgación científica y popular de la Heráldica, la vexilología y otros símbolos de las Entidades Locales: Hacia un "Corpus Emblemático Local Español".

- La figura de la FEMP como impulsora de la unificación y coordinación de la normativa simbológica de las Entidades Locales y de su divulgación.

Como se puede ver, el curso es variado y ambicioso; es evidente que, en él, se han volcado las ideas, no solamente del ponente del proyecto, sino de la propia Real Academia Matritense de Heráldica y Genealogía que, realmente, y te- niendo en cuenta que en ella se encuentran representadas tanto todas las Comunidades Autónomas españolas, como la forma de pensar de muchísimos de sus miembros pertenecientes a diversos países de Europa y de América, recoge el sentir de la mayor parte de los expertos y conocedores de estas disciplinas en el ámbito que se estudia.

Si bien el curso de Heráldica y Vexilología municipales ha sido favorablemente acogido por la FEMP y aceptada su inclusión en las programaciones futuras de la Formación Continua de la misma por su Comisión Ejecutiva en su sesión del día 31 de enero de 2007, queda aún por ver, realmente, la virtualidad final del proyecto de curso y de sus criterios docentes, así como su acogida por parte de aquellas personas e instituciones a quienes va dirigido; falta, asimismo, la plasmación del otro curso, el de Patrimonio Histórico Artístico y su estudio y aceptación; por fin, tras ello, faltará la evaluación organizativa, docente y práctica de los mismos; sólo entonces podremos llegar a auténticas conclusiones concretas.

Sin embargo, ya podemos comentar la más importante de estas conclusiones; en efecto, la presentación del primero de los cursos y la final entrega del proyecto del segundo de ellos, han permitido el inicio formal de aquellos acuerdos de colaboración entre la CECEL y la FEMP establecidos en el año 1998 y que hasta ahora no habian podido verse plasmados en una acción real.

Así, la importancia real de estos cursos radica, no ya en su propia bondad docente y en su posible aplicación práctica en los diferentes municipios, sino, y fundamentalmente, en que, puestos, así, en marcha, con ellos, estos acuerdos de colaboración, se augura una ya permanente colaboración entre ambas entidades, cuyos resultados esperamos ver aumentados en poco tiempo.
Recibido: Octubre de 2007

Aceptado: Mayo de 2008

\section{NOTAS}

1 Artículo 1. de sus Estatutos.
2 Ibidem. Artículo 2.

3 Cláusula Segunda. 4 del Convenio de colaboración citado. 